\title{
The emergence of regularity and variability in marine ecosystems: the combined role of physics, chemistry and biology
}

\author{
FORD BALLANTYNE IV ${ }^{1}$, OSCAR M.E. SCHOFIELD ${ }^{2}$ and SIMON A. LEVIN ${ }^{3}$ \\ ${ }^{1}$ Department of Ecology and Evolutionary Biology University of Kansas Lawrence, KS 66047. E-mail: fb4@ku.edu \\ ${ }^{2}$ Institute for Marine and Coastal Sciences Rutgers University 71 Dudley Road New Brunswick, NJ 08901. \\ E-mail: oscar@marine.rutgers.edu \\ ${ }^{3}$ Department of Ecology and Evolutionary Biology, Princeton University, Princeton, NJ 08544-1003. \\ E-mail: slevin@princeton.edu
}

\begin{abstract}
SUMMARY: Marine ecosystems play an integral role in the functioning of life on earth. To predict how they will respond to global changes, and to effectively manage and maintain services upon which humans rely, we must understand how biological processes at the cellular level generate macroscopic patterns in the oceans. Here, we discuss how physics and biogeochemistry influence and constrain marine ecosystem structure and function, and outline key regularities and patterns of variability that models should aim to reproduce. We identify unanswered questions regarding how size-dependent physiological and ecological processes are linked to turbulent mixing, dealing specifically with how size structure is related to mixing over a range of spatial scales and how it is linked to the fate of primary production in the sea.
\end{abstract}

Keywords: variability, turbulence, scaling, abundance, trophic interactions, modelling.

RESUMEN: LA APARICIÓN DE REGULARIDADES Y VARIABILIDAD EN ECOSISTEMAS MARINOS: EL PAPEL COMBINADO DE LA FÍSICA, LA QUÍMICA Y LA BIOLOGÍA. - Los ecosistemas marinos juegan un papel integral en el funcionamiento de la vida sobre la Tierra. Para predecir cómo van a responder a cambios globales y para mantener los servicios de los cuales los humanos dependemos, tenemos que comprender cómo los procesos biológicos a nivel celular generan patrones macroscópicos en el océano. Examinamos cómo la física y la biogeoquímica afectan y limitan la estructura y función de los ecosistemas marinos, y exponemos importantes regularidades y patrones de variabilidad que los modelos deberían reproducir. Identificamos aspectos sin resolver sobre la relación entre procesos fisiológicos y ecológicos y la mezcla turbulenta. En concreto, cómo la estructura de tamaños está relacionada con la mezcla en un rango de escalas espaciales y cómo está conectada con el destino de la producción primaria en el mar.

Palabras clave: variabilidad, turbulencia, escalado, abundancia, interacciones tróficas, modelización.

\section{INTRODUCTION}

Perhaps the greatest mandate facing global society today is the achievement of a sustainable future. As we degrade our environments, we lose the services that ecosystems provide. Clearly, as a first step we must catalogue what those benefits are, that is, the things we take directly from systems, like food, fibre and fuels, the indirect benefits from climate mediation and carbon sequestration, and the most difficult to quantify: the aesthetic and ethical. Such a cataloguing, however, is just a beginning, raising scientific challenges that cross disciplines from the molecular to the socio-political level, and that cross scales of space, time and complexity (Levin, 2010). What are the dimensions of biological diversity and ecosystem organization that underlie those services, and what mechanisms sustain their robustness and resilience (Levin and Lubchenco, 2008)? These challenges are particularly urgent for marine ecosystems, which are already providing evi- 
dence of regional and basin scale decadal shifts (Kerr 2010; Hoegh-Guldberg and Bruno 2010; Schofield et al., 2010).

Ecosystems and the biosphere are complex adaptive systems, deriving their features from evolutionary forces and ecological mechanisms operating far below the level of the whole system (Levin, 1998; 1999). As a consequence, the macroscopic patterns that characterize marine ecosystems are sustained by a combination of microscopic and macroscopic forces (Margalef, 1978). This means that we must develop approaches that allow us to scale from cells and individuals to ecosystems and the biosphere, deriving a statistical mechanics of ecosystem function (Levin, 1992). Scaling up cellular process to the biosphere requires not only the ability to predict overall biomass, but also an understanding of overall community diversity. Promising steps have been taken in this direction recently; for example Follows et al. (2007) explain aspects of the global distribution of specific classes of phytoplankton. There are, however, a variety of other regularities characteristic of marine ecosystems, and knowing these and how robust they are can provide us with not only a hierarchy of indicators of system decline, but also a set of targets for evaluating the success of modelling efforts.

Global net primary production and biogeochemistry are greatly influenced by the dynamics of marine ecosystems because biological processes catalyze and drive the flow of nutrients and energy in the oceans (Redfield, 1958; Margalef et al., 1979; Raven and Falkowski, 1999). As a result, seemingly small changes in marine ecosystem processes (e.g. shifts in temperature and stratification) can have significant consequences for global biogeochemistry and the global carbon budget because the oceans harbour the largest carbon pool associated with the global carbon cycle. It is therefore essential to improve our relatively poor understanding of how marine ecosystems will respond to continued disturbance (Pomeroy, 1974; Azam et al., 1983). Because metabolism and higher-order ecological interactions (competition, predation, etc.) are constrained by the chemical and physical environment, in order to predict how the oceans will respond to perturbations, it is critical to understand the links between the chemical environment, the physical mixing of water, and biological processes. For example, the increasing water column stratification has been hypothesized to underline the basin scale declines in phytoplankton productivity in the South Pacific (Behrenfeld et al., 2006). This mirrors the purported centennial declines in global ocean productivity (Hoegh-Guldberg and Bruno, 2010) and the projected changes associated with altered ocean circulation (Schmittner et al., 2005) can feed back to accelerate climate change (Cox et al., 2000). Detecting these changes is difficult because long-term changes are superimposed upon natural climate cycles and high frequency fluctuations, and our quantitative understanding of the physical forcing of ocean productivity remains a central challenge for biological oceanography.

The physical mixing of water, driven by the earth's rotation, local wind patterns and density gradients, creates spatial and temporal heterogeneity in ocean properties and provides the context for biological processes (Stommel, 1963). For example, chlorophyll $a$ concentrations exhibit patterns of variability across a range of spatio-temporal scales (Fig. 1). Organisms experience significant variability in environmental conditions on time scales ranging from seconds to decades and from microns to thousands of kilometres (Haury et al., 1978). Although the influence of physical variability on biological processes in the oceans has been appreciated for over half a century, the link between heterogeneity generated by physical processes and variability in ecosystem properties continues to be a focus of theoretical and empirical research in oceanography, in part because we still do not fully understand the links and feedback mechanisms (Bracco et al., 2009). An appreciation for the influential role that biological processes play in determining carbon flow and biogeochemical cycling in the oceans (Sarmiento and Toggweiler, 1984; Fasham, 2003) has prompted modellers to incorporate detailed descriptions of the links between nutrient dynamics, primary production and trophic dynamics into purely physical models. The advent of increasingly detailed descriptions of biologically driven nutrient cycling in large-scale ocean models (Leonard et al., 1999; Moore et al., 2002; Lima and Doney, 2004; Litchman et al., 2006; Follows et al., 2007) warrants a review of the links between chemical, physical and biological processes operating over a range of scales and their combined impact on ecosystem structure and function. Our goals in this paper are to help synthesize our current understanding of the links between physics, biogeochemistry and variability in ecosystem properties and to identify key questions that need to be addressed to advance our understanding of the determinants of marine ecosystem structure. First, we briefly review how mixing generates variability and discuss links between physical variability and variability associated with biological processes. Next we highlight 3 regular features in marine ecosystems: community diversity, size structure and trophic structure, and pose questions about how each is related to physical variability. Finally, we discuss the biogeochemical consequences of biological feedbacks and some implications for modelling marine ecosystems.

\section{THE PHYSICAL GENERATION OF VARIABILITY}

The physically driven mixing that occurs in the oceans depends upon complicated flow patterns and transfer of energy and momentum over a range of spatio-temporal scales. Because spatio-temporal heterogeneity in the oceans is driven in large part by physics, fluid dynamics provides a null prediction for the 


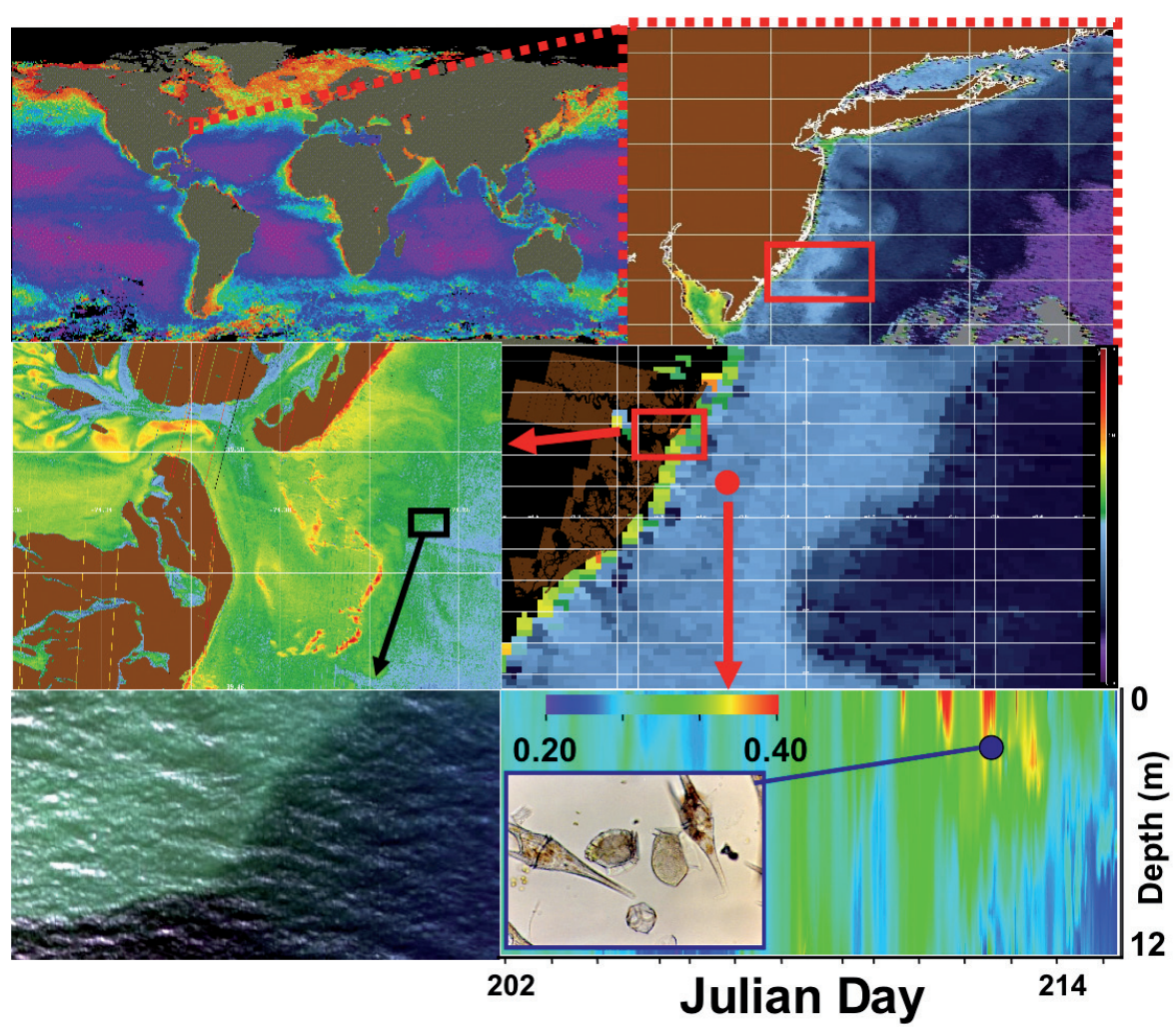

FIG. 1. - Variability in chlorophyll $a$ over a range of scales.

relationship between spatial and temporal variability in ecosystem properties (Tennekes and Lumley, 1972; Margalef et al., 1979; Levin, 1992; Falkowski and Oliver, 2007). Mixing begins at large spatial scales, where momentum is transferred as shear stress from the earth's rotation and wind to the oceans' waters, inducing flow. In the interior of the oceans at appropriate latitudes, flows can be characterized by simplified equations of motion with Coriolis terms dominating (Pond and Pickard, 1983). However, in other regions, the Gulf Stream for example, non-linear terms must be retained in equations of motion and the ratio of non-linear to frictional effects (the Reynolds number) is high, leading to the irregular mixing known as turbulence. Over a range of scales known as the inertial subrange, energy introduced by momentum is transferred with little dissipation, but is ultimately lost due to viscosity or molecular friction at scales smaller than the smallest eddies generated by turbulent mixing. The inertial subrange is delineated by Ozmidov lengths at the upper end and the Kolmogorov or inner length scale at the lower one. Kolmogorov's universal equilibrium theory posits that inner scales or microscales of length, time and velocity, all associated with the smallest eddies, are well approximated by simple functions of the kinematic viscosity of water $v\left(10^{-6} \mathrm{~m}^{-2} \mathrm{~s}^{-1}\right)$ and the energy dissipation rate per unit mass $\varepsilon$, which is assumed to equal energy input from larger scale eddies in the turbulent flow. The inner length, time and velocity scales are $\left(v^{3} / \varepsilon\right)^{1 / 4},(\nu / \varepsilon)^{1 / 2}$, and $(\nu \varepsilon)^{1 / 4}$ respectively and are much smaller than the largest eddies in turbulent flow, rendering the small-scale structure in turbulent flow statistically independent of larger scale eddies when Reynolds numbers are large (Tennekes and Lumley, 1972). Ozmidov length scales tend to be of the order of metres and inner length scales tend to be of the order of centimetres. Kolmogorov's microscales and the associated frequency spectrum provide robust predictions for how three-dimensional turbulent mixing generates variability independent of biological processes in the inertial subrange.

Although the $k^{-5 / 3}$ energy spectrum, which predicts how variability scales with frequency (Kolmogorov, 1941a;b), has proven to be robust even when its basic underlying assumptions are not met (Phillips, 1991), relating observed biological variability to turbulent mixing is a challenge. First, the limitations of current instrumentation make resolving variability over the inertial subrange difficult. And second, deviations from the Kolmogorov prediction can be generated via multiple processes (Franks, 2005). For example, when plankton interactions (Powell and Okubo, 1994) and size structure (Poulin and Franks, 2010) are incorporated into models, spectral slopes can vary greatly. However, observed spatio-temporal variability that deviates from null expectation of the $k^{-5 / 3}$ energy spectrum suggests that additional processes or constraints are exerting influence over a range of scales. Deviations in variables associated with biological activity may indicate that biological processes are expending energy to dissipate energy inputs from physical processes, thereby maintaining spatial heterogeneity, or 
disperse, effectively smoothing physically driven variability. Understanding the scales at which these deviations occur and what drives them is key because this is where predictions based only on physics break down. It is critical to identify these scales if we hope to understand and predict how marine ecosystems are likely to respond to perturbations amidst all the physically driven background variability.

The complete context for biology in marine ecosystems is provided by physical mixing, the light environment and redox conditions, largely determined by oxygen concentrations. Increased energy input from wind increases the degree of mixing in the surface ocean and serves to lower the pycnocline, increase nutrient inputs to the euphotic zone and maintain high oxygen concentrations, all of which have important consequences for biological processes. Over half a decade ago, Sverdrup (1953) pointed out how mixing could influence ecosystem processes. Using a simple model, he showed that it is necessary for the nutricline, whose depth is intimately tied to the depth of the pycnocline and energy input, to be shallower than critical light depth in order for significant primary production (e.g. phytoplankton blooms) to occur. This is perhaps the first example of how physical mixing and the chemical environment were integrated to make a general prediction about ecosystem response to a variable environment. Although Sverdrup's reasoning is logically sound, the interpretation of critical depth is inherently scale- and taxondependent (Smetacek and Passow, 1990), making its general application difficult. Nevertheless, phytoplankton growth results in severe drawdown of concentrations of limiting resources, namely nitrogen and phosphorus, but also creates anoxia and hypoxia from increased rates of decomposition in slightly deeper water, significantly altering redox state. As a consequence, variability in the chemical and physical environment in the oceans can be more predictable with depth than across space. For exemple, the abundance of different species can vary predictably with depth (Belyayeva, 1970; Letelier et al., 1993; Bidigare and Ondrusek, 1996; Johnson et al., 2006; DeLong et al., 2006) as well as latitude (Davis and McGillicuddy, 2005) and longitude (Cavender-Bares et al., 2001). In all cases, abundance of particular taxonomic groups is closely tied to the chemical and physical environment.

Mixing can influence phytoplankton community composition by changing the chemical environment and shifting life-history trade-offs, many of which are dictated by body size (Margalef et al., 1979). Differential ability to acquire nutrients confers differential competitive ability in different environments, which means that distinct phytoplankton communities occur in disparate mixing regimes (Litchman et al., 2006; Falkowski and Oliver, 2007). However, physically generated variability can also promote coexistence among species (Scheffer et al., 2003). Mixing can reduce the disadvantage larger cells face from sinking faster than smaller cells (Smayda, 1970; Rodríguez et al., 2001; Huisman et al., 2002;
Irwin et al., 2006) and from reduced surface to volume ratios, critically important in determining rates of nutrient uptake (Chisholm, 1992; Irwin et al., 2006; Strom, 2008; Yoshiyama and Klausmeier, 2008). For example, cyclonic eddies have been shown to increase inorganic $\mathrm{N}$ concentrations and to increase the abundance of large species (Vaillancourt et al., 2003). In stable environments, smaller body sizes characteristic of picoplankton are predicted to be optimal, but predation by zooplankton and increased nutrient supply increase optimal body sizes for phytoplankton (Jiang et al., 2005; Irwin et al., 2006). Increased mixing, turbulence in particular, also increases the susceptibility to predation by decreasing sensitivity to hydrodynamic signals (Hwang et al., 1994; Gilbert and Busky, 2005) as well as modifying behaviour (Moison et al., 2009) and cell morphology (Thomas and Gibson, 1990). Although much work has focused on nutrient acquisition and competition among phytoplankton taxa (Falkowski and Oliver, 2007; Yoshiyama and Klausmeier, 2008) as key determinants of community structure, the importance of higher trophic interactions has recently been stressed (Jiang et al., 2005; Strom, 2008). Though we do not fully understand the advantages and disadvantages associated with changes in body size across different mixing regimes and chemical environments, the complex network of feedbacks between the chemical environment, biological nutrient transformations and heterogeneity are surely linked to organism body size.

\section{IDENTIFYING SCALES ASSOCIATED WITH BIOLOGICAL REGULARITIES}

Physically driven mixing is primarily responsible for generating variability at larger scales, which is subsequently transferred in a regular fashion over a range of intermediate scales and ultimately lost at the smallest scales (Kolmogorov, 1941a,b). Energy, which drives mixing, and chemical inputs are realized over large spatio-temporal scales (basin to mesoscale phenomena), but the majority of biological processing (e.g. metabolism, grazing and decomposition) is performed by microorganisms at cellular scales (micrometres to centimetres). This separation of scales can decouple biology from physics and makes identifying the scales at which decoupling occurs critical for predicting how ecosystems will respond to changes in circulation patterns and geochemical inputs. Over intermediate scales, of the order of 5-20 kilometres, variability in aggregated measures of biological activity, e.g. total biomass or primary production, is driven predominantly by physical mixing (Lekan and Wilson, 1978; Weber $e t$ al., 1986; Yoder et al., 1987), and phytoplankton have been shown to act as tracers over 10- to $100-\mathrm{km}$ scales (Denman and Abbot, 1994). At smaller scales, community interactions (competition, predation, parasitism, etc.) are likely to be more instrumental in determining ecosystem properties. Similar scale dependence exists in the temporal realm. At frequencies of less than $24 \mathrm{~h}$, 

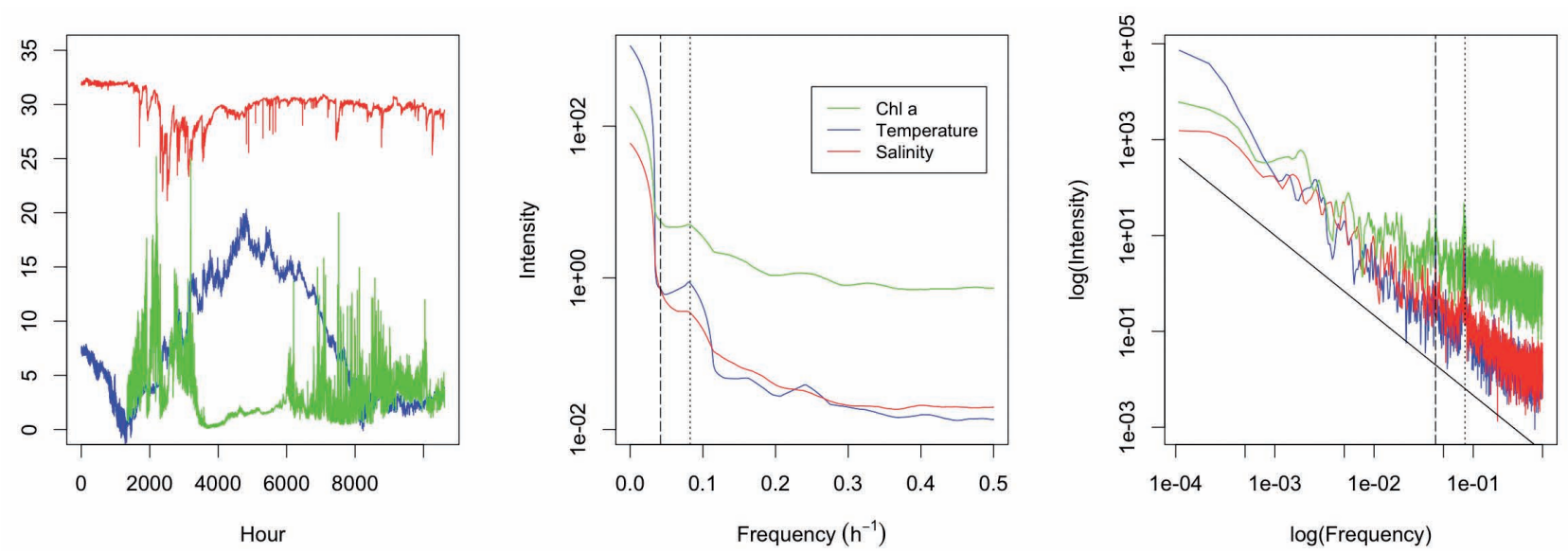

FIG. 2. - Variability in chlorophyll $a$, temperature, and salinity over a range of time scales. Left panel are the raw time series from Gulf of Maine Ocean Observing System (GOMOOS) buoy DO1, in Lower Harpswell Sound, from December 12, 2006 through March 31, 2008. Centre panel shows smoothed periodograms for the time series. Dashed line is 24 hour frequency and the dotted line is 12 -hour frequency. Right panel shows log transformed variance spectra for the time series. Solid line is the $-5 / 3$ Kolmogorov prediction (see text) and the dashed and dotted lines are the same as in the centre panel.

variance spectra for chlorophyll $a$ deviate from spectra for temperature and salinity, both of which appear to conform to the Kolmogorov prediction (Fig. 2). It is interesting to note the apparent concordance with the $\mathrm{k}^{-5 / 3}$ energy cascade because the observed frequency range is presumably outside of or only partially overlaps the inertial subrange. Regardless of what is conspiring to generate variance spectra consistent with the Kolmogorov prediction over this frequency range, it is apparent that biological processes dictate patterns of variability in chlorophyll $a$ at shorter time scales. In particular, a greater proportion of total variability in chlorophyll $a$ concentration is generated at high frequencies, which could be the result of large individual plankton cells or aggregates (Levin et al., 1989; Grünbaum and Okubo, 1994; Grünbaum 1994; Flierl et al., 1999; Franks, 2005). Thus, it becomes important to understand how ecosystem processes respond to, and potentially feed back on, abiotically generated variability across scale in the marine environment. Determining the relative influence of abiotic and biological processes occurring across scales on observed ecosystem properties remains a challenge (Martin, 2003; Bracco et al., 2009), and one that must necessarily be overcome to predict the response of ecosystem processes to continued perturbation.

The generality of spatial and temporal variability in aggregated measures of biological activity (biomass, chlorophyll $a$, etc.) has been the subject of intense study for decades. A close correspondence between variance spectra of physical variables, such as temperature and salinity, and measures of biological activity have been thought to implicate turbulent mixing as a key factor in generating spatio-temporal variability in ecosystem structure. However, Franks (2005) clearly articulates that variance spectra alone are not enough to unambiguously determine underlying causes of variability. Patterns of variability are more informative if put in the context of a model with dynamics at the appropriate temporal and spatial scales. The end result of the interplay between physical mixing and ecological processes is often a heterogeneous or patchy distribution of biomass at the surface of the ocean (Abraham, 1998). For example, the interaction between mixing and rate of reproduction determines the degree of "patchiness" of phytoplankton (Denman et al., 1977). The patches are more prevalent at intermediate spatial scales (5-20 $\mathrm{km}$ ). If predators and prey within these patches disperse at roughly the same rates, which would occur if they are similar in size, mixing can increase their encounter rates, but a discrepancy in dispersal rates (predators and their prey can have Reynolds numbers differing by over 3 orders of magnitude) will reduce the potential for trophic interactions (Granata and Dickey, 1991). For larger plankton with longer generation times, smaller-scale spatial variability $(\leq 1 \mathrm{~km})$ can be generated by individuals that initially experienced variability associated with the largest turbulent features in the oceans, occurring over hundreds of kilometres (Abraham, 1998). The key determining factor is the relationship between the Kolmogorov length (approximately $1-10 \mathrm{~mm}$ ) and velocity (approximately $0.1-1 \mathrm{~mm} \mathrm{~s}^{-1}$ ) scales, and organism size (Granata and Dickey, 1991). If patches persist, they can stimulate further aggregation by other organisms and be exploited by predators at multiple higher trophic levels in a matter of minutes, potentially accelerating carbon flow through the microbial loop (Seymour et al., 2009). Using dimensional arguments, Grünbaum (2002) derived a criterion for determining whether resource patches of particular size and longevity are available to foragers with particular foraging time scales. Increased variability or patchiness creates the potential for increases in biogeochemical rates. Aggregates increase spatial variability, and if a non-linear relationship exists between patch size or duration and rates of biogeochemical or ecological processes, gross fluxes could be altered. Patchiness in the distribution of phytoplankton can occur with depth 
as well. Hydrodynamic torque can disrupt the ability of phytoplankton to orient with respect to gravitational torque, spinning phytoplankton and causing them to aggregate into thin dense layers in the euphotic zone (Durham et al., 2009). Continued upward swimming of deeper phytoplankton further aggregates phytoplankton into patches that can persist for several minutes (see below for more discussion of thin layers).

Ultimately, the intrinsic time scale associated with a particular variable of interest will determine the extent to which turbulent mixing influences variability. Over long times scales and for variables with slow relaxation times, such as salinity and temperature, turbulent diffusion is the dominant process generating observed variability, but variability in small-scale phenomena, such as phytoplankton variance spectra, must be determined by short-time-scale processes, not turbulent mixing (Bracco et al., 2009). As can be seen in Figure 2, variability in chlorophyll $a$ concentration appears to be tightly linked to physically generated variability over intermediate time scales, but deviates from variability produced by physical mixing at short and long time scales. The departure of the chlorophyll $a$ spectrum from salinity and temperature spectra at the shortest time scales suggests that biological processes are responsible for generating observed high frequency variability. In marine communities, patchiness is observed at almost every scale of observation-in the zooplankton and those that feed on them, in the phytoplankton, and in the underlying physical properties of the environment. Patterns of variability across trophic levels and departures from the spectra associated with abiotic features suggest that physical features may account for the patchiness on the largest scales, but that biological features-such as swimming behaviour of zooplankton-must be invoked to explain smallerscale patchiness (Levin et al., 1989; Levin, 1992; Bearon et al., 2004). As a consequence, we should not be surprised that purely physical models often perform poorly when making predictions for dynamics that occur over the course of hours in marine ecosystems. We need to understand ecological and biogeochemical interactions at short time scales before we can accurately predict dynamics across all scales. Despite decades of intense study, a coherent statement linking turbulent mixing and variability is missing (Martin, 2003; Bracco et al., 2009), in part because the influence of swimming on patterns of variability has yet to be fully explored (Granata and Dickey, 1991; Kamykowski et al., 1992; 1998; Bracco et al., 2009). It is clear that we still have much to learn about the causes of variability in biological processes at the finest scales, but that variability across intermediate scales can be well predicted from physical mixing alone. However, if we wish to scale up ecosystem dynamics from the scales at which they occur to scales meaningful to humans, it is critical to understand why biologically-driven variability deviates from physically driven variability at the smallest scales. One consolation is that the scales at which statistical predictions from fluid dynamics fail are the scales at which experimentation is possible (Guadayol et al., 2009).

\section{REGULARITIES IN MARINE ECOSYSTEMS}

\section{Community structure and diversity}

Although the highly variable marine environment creates the potential for myriad micro-environments and ecological interactions, marine ecosystems often exhibit striking regularities. As in terrestrial ecosystems, predictable gradients in species richness and community similarity, as well as oscillations in community structure, are found in the oceans. Using the intergenic spacer region between $16 \mathrm{~S}$ and $23 \mathrm{~S}$ rRNA to describe marine bacterial genotype diversity, Fuhrman et al. (2008) demonstrate a latitudinal diversity gradient for bacterial plankton with the highest sequence diversity found at the equator. This gradient in the richness of sequence diversity appears to be tightly linked to temperature. Additionally, the idea of $\beta$ diversity, or the turnover of species across space, can be easily applied to marine plankton communities. Phytoplankton community dissimilarity, the result of $\beta$ diversity, tends to asymptote at approximately $20 \mathrm{~km}$ both along and across the continental shelf in British Columbia (Mackas, 1984), whereas zooplankton community dissimilarity asymptotes at approximately $35 \mathrm{~km}$ across and at approximately $100 \mathrm{~km}$ along the shelf. These results suggest important characteristic horizontal scales for vertically integrated community structure that differ between trophic groups. Plankton community structure also varies predictably over time. Bacterial plankton exhibit regular annual fluctuations in community structure that are driven by both abiotic and biotic processes (Fuhrman et al., 2006). Zooplankton community structure has also been linked to flow patterns in the oceans (Mackas et al., 2001). Such predictable variability highlights the inherent scale dependence of observations (Levin, 1992). In general, estimates of variance increase with window or grain size and will attenuate in finite systems. The point at which variance saturates suggests a natural scale associated with the extent of underlying causal processes, which for the study of Mackas (1984) are approximately $20 \mathrm{~km}$ for phytoplankton, and either 35 or $100 \mathrm{~km}$ for zooplankton, depending on direction (along or off shore). Therefore, multi-species plankton models, set in the context of physical oceanography models, should exhibit patterns of $\beta$ diversity and characteristic scales on the order of kilometres to tens of kilometres, consistent with empirical patterns (Starr and Mullin, 1981; Mackas, 1984). Additionally, there is increasing evidence that biological behaviour combined with turbulent shear can lead to the formation of small-scale features of a metre or less in both phytoplankton and zooplankton communities (McManus et al., 2008; Cheriton et al., 2009; Moline et al., 2009), but these so-called "thin 
layers" can also be produced by shear alone (Franks, 1995; Birch et al., 2008). The biomass associated with these layers can represent the major feature present in the water column (Sullivan et al., 2009). While presence of these thin layers has only been documented in the last decade, current and future efforts are focused on mapping their quantitative significance in the ocean. These small scale features will represent new challenges for ocean models, because they need to describe processes operating over non-hydrostatic scales.

\section{Abundance-size scaling of plankton}

The scaling of abundance with organism size also exhibits some uniformity across disparate habitats and environmental conditions, despite the fact that life-history trade-offs and ecological interactions vary with body size. One of the most striking regularities in marine ecosystems involves the biomass spectrum, which of course is intimately connected with the flow of energy across scales. Sheldon et al. (1972) observed that aquatic ecosystems exhibit a power law decrease in abundance as body size increases across a broad range of size scales from the smallest particles to the largest consumers. This has inspired a wealth of theoretical efforts to explain these patterns, largely couched in consideration of the trophic web (Kerr, 1974; Platt and Denman, 1977; Silvert and Platt, 1978; Stock et al., 2008). There has since been considerable discussion about the exact value of the scaling exponent and the spatio-temporal scales over which we would expect uniform scaling to apply (empirically calculated exponents range from $-5 / 3$ to $-2 / 3$ (Finkel, 2007). Rodríguez (1994) argues that this "primary" scaling results from common constraints that all organisms face when acquiring resources, distributing them and metabolizing them. However, such robust size-abundance scaling breaks down when a narrower range of body sizes is considered or when local environmental conditions are driven primarily by physical processes. This argument leads to a fundamental question yet to be answered: how is robust size-scaling of plankton tied to physical mixing over a range of spatial scales and the intrinsic constraints placed on single-celled organisms in the marine environment? Data compiled by Chisholm (1992) show that picoplankton comprise virtually all plankton biomass in N-poor waters but comprise a small fraction of the total plankton biomass at higher nutrient concentrations, supporting the optimal body size relationships derived by Jiang et al. (2005) and reinforcing the notion that size-abundance scaling may be scale-dependent. Interestingly, picoplankton density is relatively uniform throughout the world's oceans, which suggests that size structure of larger size classes may be "superimposed" on relatively constant picoplankton biomass.

Increased mixing, often driven by upwelling, increases local nutrient concentrations and diatom abundance, 2 to 3 orders of magnitude larger than cyanobacteria, which dominate the ensuing plankton biomass

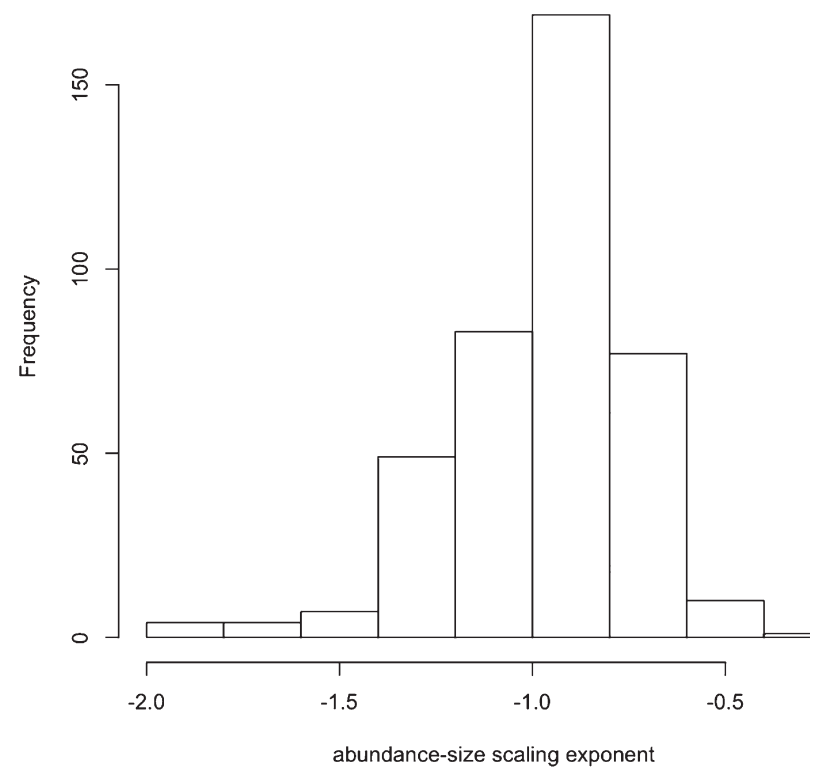

FIG. 3. - Abundance-body size scaling exponents for AMT cruises 12,13 and 14. Body size is computed as length ${ }^{3}$.

(Rodríguez et al., 2001) and change the slope of the size spectrum. Intermediate upward mixing velocities, of the order of $5 \mathrm{~m} \mathrm{~d}^{-1}$, increase total carbon in the euphotic zone by buoying these larger species. The fact that the community size spectrum is well characterized by a power law implies that the same size scaling will hold for individual species that exhibit some degree of size polymorphism (Rinaldo et al., 2002). Bacteria, despite varying forms and functional types, appear to conform to this prediction. Universal size scaling in marine ecosystems, which indicates the absence of a "preferred" body size, is certainly surprising given the variability in the chemical and physical environment of the oceans (Rinaldo et al., 2002). Another way to phrase the above fundamental question is: what variance signature is required to reconcile the enormous shift in community composition observed by Chisholm (1992) with constant size scaling observed by many others? A single cause for the shape of the size spectrum is unlikely (Steele and Frost, 1977), but the self-organization occurring over ecological and evolutionary time scales implied by such consistent size scaling begs for an explanation (Rinaldo et al., 2002). Poulin and Franks (2010) recently demonstrated how simultaneous top-down and bottom-up control can influence size structure, but such ecological dynamics have yet to be fully placed in the context of mixing across a range of spatio-temporal scales.

More recent analyses of abundance-body size scaling shed additional light on how body size is tied to organization in marine ecosystems. Data presented by $\mathrm{Li}$ (2002) and Cermeño et al. (2006) exhibit -3/4 power scaling of abundance with cellular $\mathrm{C}$ content and volume respectively. A histogram of size-abundance scaling exponents for different locations and depths for the Atlantic Meridional Transsect (AMT) cruises 12, 13 and 14 is plotted in Figure 3. The modal value is 


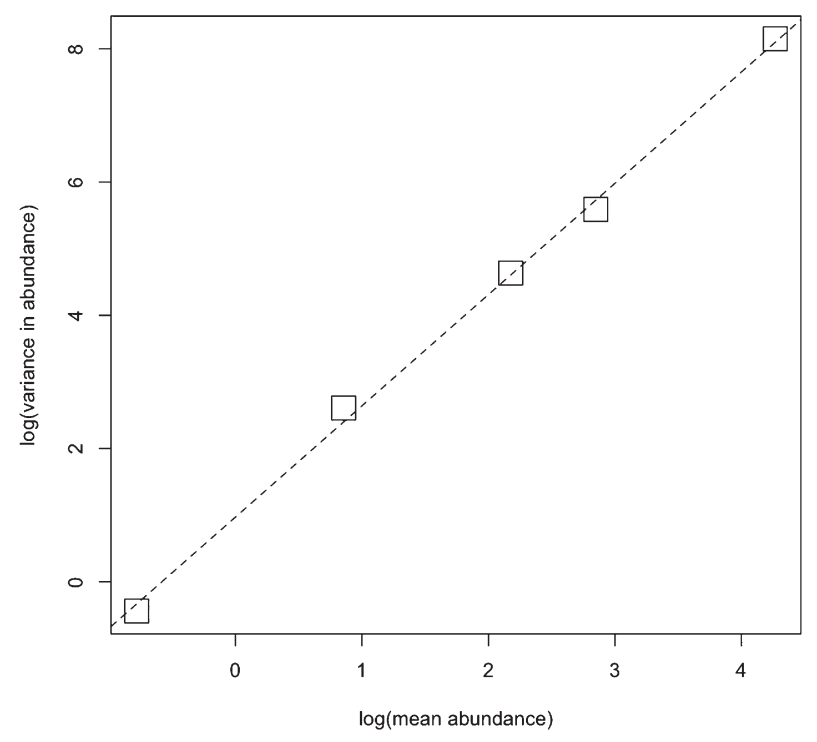

FIG. 4. - Taylor's power law for AMT phytoplankton size class data. Data transformed using natural logarithms. The slope of the log-log regression is $5 / 3$ with $R^{2}=0.9975$

consistent with values in $\mathrm{Li}$ (2002) and Cermeño et al. (2006), but we see significant variability, presumably driven by heterogeneity among individual sites and depths. Surprisingly, no relationship exists between scaling exponent and latitude or depth (unpublished results). However, spatial variance exhibits robust scaling with mean abundance, which is obviously tied to body size. Taylor's power law (Taylor, 1961), in which the logarithm of variance in abundance is plotted as a function of the logarithm of mean abundance, for AMT phytoplankton size class data is shown in Figure 4. Because the scaling exponent is $5 / 3$, the coefficient of variation for phytoplankton abundance decreases with mean abundance (Ballantyne, 2005), meaning that larger, less numerous phytoplankters exhibit more relative variation in abundance across space than do their smaller counterparts. It is not immediately obvious what is responsible for generating the exponent of $5 / 3$, but such a consistent mean-variance scaling relationship is worthy of further study.

\section{Trophic structure}

The fact that the dominant groups of primary producers in the ocean are all single-celled organisms both reflects the importance of physical processes in structuring marine ecosystems and has important consequences for trophic dynamics and marine food webs. The physical stress associated with living near the surface of the open ocean, low nutrient availability and severe grazing pressure has exerted strong selection against larger body sizes. Building and maintaining large multi-cellular bodies requires too much energy and time to be a viable strategy. Because nutrient acquisition occurs across cell surfaces and occurs predominantly by diffusion, larger cells are at a distinct disadvantage. Additionally, larger cells are often the primary targets of grazers because they take significantly longer to grow and divide, which exposes each individual cell to greater predation pressure. The major consequence of strong size selection is that the biomass of the primary producer pool in the ocean turns over on a time scale of days. All this primary production has to go somewhere and there are only 3 places for it to go: up the food web, into the microbial loop (Azam et al., 1983) or out of the euphotic zone. The latter accounts for a minimal fraction of total production, $15 \%$ on average (Falkowski et al., 1998), leaving the microbial loop and grazing food webs responsible for funnelling off the rest. Although the microbial loop can metabolize a significant fraction of primary production, the remaining primary production, not lost to respiration, is grazed and transferred up through the marine food web. However, changes in trophic structure can significantly alter the flow of $\mathrm{C}$ and other nutrients through food webs, affecting gross rates of respiration and $\mathrm{C}$ flux through the euphotic zone (Walsh, 1981). The transformation of primary production along these multiple pathways leads to another fundamental question: how is the proportion of primary production consumed by the microbial loop related to highly constrained size structure, and what is the relevant scale for addressing this question? The role of viruses and higher-order interactions on the flow of carbon and nutrients in marine ecosystems is surely linked to the size spectrum of the primary producers. Viruses may help retain nutrients in the euphotic zone but may also increase bacterial respiration by one third (Fuhrman, 1999). The importance of predation in dictating size spectra has long been known (Steele and Frost, 1977), but in order for us to be able to predict the effects of climate change on ecosystem processes, food web interactions must be put in the context of physical mixing (Fuhrman, 1999).

The efficient transfer of primary production up oceanic food webs, due in large part to the similarity in predator and prey sizes, has important implications for ecosystem structure. Higher trophic levels contain significant biomass relative to lower trophic levels, and changes in primary production are tightly linked to the production of fish biomass. In contrast to terrestrial ecosystems, inverted biomass pyramids can occur in marine ecosystems in the absence of significant fishing pressure because rates of production and turnover are so high in the oceans (Demartini et al., 2008). As nutrient availability usually limits primary production and mixing influences nutrient availability (Oschlies, 2002; Vaillancourt et al., 2003), changes in mixing regimes can be linked to changes in primary production (Walsh, 1981). Over evolutionary time, changes in primary production have influenced diversification and trophic complexity in marine ecosystems (Bambach, 1993). Across space, heterogeneity in primary production is intimately tied to mixing, especially in upwelling regions (Walsh, 1981), but local conditions can also influence patterns of pri- 
mary production. For example, if wind speed exceeds $5 \mathrm{~m} \mathrm{~s}^{-1}$, the energy input is great enough to smooth production to biomass ratios (Therriault et al., 1978). The range of time scales associated with zooplankton grazing of primary production and subsequent consumption of zooplankton by fish larvae is consistent with the time scales of dominant variability in ocean currents (Denman et al., 1989). However, higherlevel trophic interactions can feed back to influence variability initially generated by physical mixing. Critical phytoplankton patch size increases in the presence of herbivory (Wroblewski et al., 1975), and variability in phytoplankton biomass is influenced by krill predation as well as mixing (Weber et al., 1986). However, variability in krill abundance is relatively constant over the range of scales associated with phytoplankton variance scaling, indicating that krill are less influenced by physical processes than are the primary producers. As a rule of thumb, more mixing means greater nutrient availability, which results in greater primary production and larger plankton (Irwin et al., 2006; Falkowski and Oliver, 2007). Despite the importance of fine-scale variability, for some questions, averaging the effects of mixing across scales throughout the euphotic zone is still informative (Franks, 2002).

Regularities in size structure (for example the socalled Sheldon spectrum discussed above) and universal constraints on metabolism have enabled researchers to link biomass and energy fluxes at the level of unicellular organisms to far-ranging top predators. For example, the efficient transfer of primary production up through food webs has made it possible to estimate total potential catch throughout the world's oceans (Ryther, 1969; Walsh, 1981). Such efficient transfers through consumption enable relationships between biomass and size class, time scales associated with transfers between trophic levels and ecosystem respiration to be predicted from allometric dependence of growth and metabolism on body size (Platt and Denman, 1977; Denman et al., 1989). Furthermore, the shape of the fish size spectrum has been used to infer the degree to which humans have exploited marine ecosystems (Jennings and Mackinson, 2003). Shifts in the size spectrum indicate that different components of marine ecosystems may exhibit differential responses to environmental heterogeneity generated by physical mixing, largely determined by body size. Models with additional trophic detail and explicit size structure suggest that transfers of biomass from smaller to larger size classes need to be more fully integrated in order to reproduce smoother empirically observed size spectra (Silvert and Platt, 1978). Stock et al. (2008) show that the observed power law distribution for abundance in size classes emerges from such a trophic model that balances ingestion by one size class with production by the level below, and that the slope of the log-log relationship is determined by the fraction of ingested prey converted to new biomass.

\section{BIOLOGICALLY DRIVEN FEEDBACKS}

Ecosystem processes can also exert feedbacks on the physical-chemical environment in the oceans. For a long time, questions about the generation of ecosystem structure have focused on determining whether physics drives biology or biology drives physics (Margalef, 1978; Bracco et al., 2009). Depending on the property in question, the relative importance of physical versus biological processes can vary substantially. As described above, mixing strongly influences phytoplankton patchiness over tens of kilometres, but light absorption by phytoplankton can create a pressure gradient from a temperature gradient and induce a flow velocity (Edwards et al., 2001), albeit small. However, biological feedbacks are more influential in determining the chemical environment in the oceans because biological processes are responsible for the majority of the chemical transformations in the sea. Chemical transformations occur orders of magnitude more rapidly because of biology, which is why biological processes dictate the biogeochemistry of the oceans. In nutrient poor regions of the oceans, competition for nutrients among phytoplankton is strong and results in significant drawdown of inorganic nitrogen $(\mathrm{N})$ and phosphorus $(\mathrm{P})$ concentrations, to almost un-detectable levels. But because $\mathrm{N}$ fixation is a biologically-driven process, $\mathrm{N}: \mathrm{P}$ stoichiometry in the oceans is largely a product of ecosystem processes. It is perhaps the best example of an emergent property in ecosystem science.

The N:P stoichiometry of the euphotic zone has been the basis for much inference about ecosystem processes in the oceans, yet we do not fully understand how metabolism and nutrient requirements ultimately determine observed N:P (Klausmeier et al., 2004). Departures of inorganic N:P stoichiometry from Redfield values typical of phytoplankton (C:N:P of 106:16:1) are widely used to infer nutrient limitation of phytoplankton and the magnitude of $\mathrm{N}$ fixation (Gruber and Sarmiento, 1997; Karl et al., 2001; Cavender-Bares et al., 2001; Deutsch et al., 2007). For example, inorganic $\mathrm{N}: \mathrm{P}$ in the North Atlantic during the summer and in the Pacific throughout the year is less than 16:1, potentially indicating strong selection for $\mathrm{N}$ fixation (Karl et al., 2001; Cavender-Bares et al., 2001). However, during the winter in the North Atlantic, large inputs of nitrate, resulting from wind-driven mixing, increase inorganic N:P to significantly greater than $16: 1$, suggesting greater relative $\mathrm{P}$ limitation. Such inference is predicated on the assumption that phytoplankton $\mathrm{N}: \mathrm{P}$ does not vary from the Redfield value of approximately $16: 1$, and that phytoplankton draw the most limiting nutrient down to the lowest concentration. However, phytoplankton N:P varies with nutrient status/limitation (Geider and LaRoche, 2002; Bertilsson et al., 2003) and as a function of inputs (Karl et al., 2001), potentially confounding such inference through poorly understood feedbacks. Furthermore, models of coupled phytoplankton-nutrient dynamics require refinement to 
eliminate a significant discrepancy between predictions for the relationship between phytoplankton $\mathrm{N}: \mathrm{P}$ and inorganic N:P and empirically observed values (Ballantyne et al., 2010). Despite intuition for what may govern the likely extremes of phytoplankton N:P (Klausmeier et al., 2004), how the joint influence of phytoplankton nutrient uptake and nutrient recycling conspire to generate the Redfield value of 16:1 for deep water inorganic $\mathrm{N}: \mathrm{P}$, which integrates euphotic zone metabolism, is still a mystery. And because mixing has such a significant influence on nutrient concentrations and can mediate the effects of turbulence (Iverson et al., 2010), nutrient dynamics associated with phytoplankton need to be more explicitly linked to physical mixing and the variability it produces.

\section{IMPLICATIONS FOR MODELING MARINE ECOSYSTEMS}

Modelling and predicting the global climate system, of which the oceans play an integral part, is one of the remaining grand challenges in science. The inherent difficulty stems from the fact that physics, chemistry and biology all interact to generate ocean dynamics, but not necessarily over the same spatiotemporal scales. Ocean circulation models are more advanced than their biological counterparts, because of historical considerations, but also because universal physical constraints have been accepted for over a century. We have learned much about the constraints on biological processes, but what we know has yet to be fully incorporated into physical models. We have also made many observations that can guide us in the processes of integrating physics, chemistry and biology into synthetic ocean ecosystem models, the type that will allow us to predict how the oceans will respond to continued and future perturbations. The following lays out suggestions for what needs to be incorporated into future models, and lists the biological properties that such synthetic models need to reproduce in order to be considered predictive.

First, models must be grounded in thermodynamics. Energetic considerations from equilibrium thermodynamics provide a basis for determining the possible metabolic pathways in a particular environment, and predicting the sequence in which redox reactions will occur in nature. Microbes that are able to generate energy at the highest rates seem to be better at competing for electron donors and acceptors, meaning that the most energetically favourable reaction will dominate over other less favourable reactions in a particular environment. As a consequence, microbial communities will exploit the most energetically favourable metabolic pathway (Morel, 1983), which has consequences for biogeochemical fluxes, community composition and evolution (Quigg et al., 2003). In a homogeneous environment we should, in theory, be able to predict equilibrium concentrations of redox species as a function of pe and $\mathrm{pH}$. Such predictions should reproduce observed nutrient concentrations and should be tied to $\mathrm{C}$ flux between the oceans and the atmosphere. However, the environment for phytoplankton in the oceans is far from equilibrium, and thus, the interplay between equilibrium thermodynamics and variability needs to be addressed more directly in future modelling efforts.

Recent advances in DNA and RNA collection and sequencing techniques have the potential to provide insight into how microbial metabolism feeds back into physically generated heterogeneity and ultimately generates observed variability in ecosystem features. However, interpreting such data in the context of ecosystem functioning remains a significant challenge because mixing creates a dynamic environment (Falkowski and de Vargas, 2004). Additionally, the gap between raw DNA sequences collected in the oceans and gene expression and ecosystem function is far from being bridged, although recently in situ gene expression has been characterized for well studied taxa (Frias-Lopez et al., 2008). The extent to which relatively easily collectible in situ genomic and transcriptomic data can inform future models needs to be determined. In particular, it would be very useful to compare patterns of spatial variability in gene presence and expression to empirical patterns of $\beta$-diversity for plankton described by Mackas (1984) and Starr and Mullin (1981). Such a comparison would identify meaningful scales for averaging over meta-genomes and transcriptomes for bacteria, which would complement our knowledge for phytoplankton and zooplankton.

Perhaps the greatest challenge lies in integrating size-dependent life-history trade-offs and ecological interactions with physically generated variability at similar scales. Litchman et al. (2006) and Follows et al. (2007) have made significant strides toward such integration, but at significantly coarser scales than those at which life-history trade-offs, predation and competition occur. Optimal phytoplankton size is tightly linked to nutrient availability (Falkowski and Oliver, 2007; Yoshiyama and Klausmeier, 2008) and buoyancy (Smayda, 1970; Rodríguez et al., 2001), but placing trade-offs directly into the context of the Kolmogorov energy cascade is necessary to link microscopic interactions to ecosystem-level patterns. Sizestructured trophic interactions, which are responsible for generating patterns of abundance across trophic levels (Stock et al., 2008), must also be placed directly in the context of the energy cascade, because mixing influences encounter rates between prey and predators (Weber et al., 1986).

Finally, there are key features that models need to reproduce. First, variability in biological variables needs to scale with a smaller exponent than predicted by the Kolmogorov spectrum at the finest scales. Second, biological variability must match predictions from physics over intermediate scales. Third, body size-abundance relationships should exhibit some variability, but on average should be characterized by an 
exponent of close to -1 . And last, variability in the concentrations of inorganic $\mathrm{N}$ and $\mathrm{P}$, as well at particulate $\mathrm{N}: \mathrm{P}$, should be bounded by long-term data sets.

\section{ACKNOWLEDGEMENTS}

We thank Paul Falkowski, Peter Franks and an anonymous reviewer for comments that greatly improved the manuscript. This work was partially supported by DARPA Grant HR0011-09-1-0055, Predictive Biology: Adaptability, Robustness and the Fundamental Laws of Biology, by a grant from the Office of Naval Research MURI Espresso programme (N000140610739), a grant from the National Science Foundation, Dimensions: Biological controls of ocean $\mathrm{C}: \mathrm{N}: \mathrm{P}$ ratios (OCE-1046001), and also by the Cooperative Institute for Climate Science (CICS) of Princeton University and the National Oceanographic and Atmospheric Administrations (NOAA) Geophysical Fluid Dynamics Laboratory (GFDL).

\section{REFERENCES}

Abraham, E.R. - 1998. The generation of plankton patchiness by turbulent stirring. Nature, 391: 577-580.

Azam, F., T. Fenchel, J.G. Field, J.S. Gray, L.A. Meyer-Reill and F. Thingstad. - 1983. The ecological role of water-column microbes in the sea. Mar. Ecol. Progr. Ser., 10: 257-263.

Ballantyne, F. - 2005. The upper limit for the exponent of Taylor's power law is a consequence of deterministic population growth Evol. Ecol. Res., 7: 1213-1220.

Ballantyne, F., D.N.L. Menge and J.S. Weitz. - 2010. A discrepancy between predictions of saturating nutrient uptake models and nitrogen to phosphorus stoichiometry in the surface ocean. Limnol. Oceanogr., 55: 997-1008.

Bambach, R.K. - 1993. Seafood through time: changes in biomass, energetics and productivity in the marine ecosystem. Paleobiology, 19: 372-397.

Bearon, R.N., D. Grunbaum and R.A. Cattolico. - 2004. Relating cell-level swimming behaviors to vertical population distributions in Heterosigma akashiwo (Raphidophyceae), a harmful alga. Limnol. Oceanogr., 49: 607-613.

Behrenfeld, M.J., K. Worthington, R.M. Sherrell, F.P. Chavez, P. Strutton, M. McPhaden and D.M. Shea. - 2006. Controls on tropical Pacific Ocean productivity revealed through nutrient stress diagnostics. Nature, 442: 1025-1028.

Belyayeva, T.V. - 1970. Taxonomy and distribution patterns of planktonic diatoms in the equatorial Pacific. Oceanology, 10: 101-107.

Bertilsson, S., O. Berglund, D.M. Karl and S.W. Chisholm. - 2003. Elemental composition of marine Prochlorococcus and Synechococcus: Implications for the ecological stoichiometry of the sea. Limnol. Oceanogr., 48: 1721-1731.

Bidigare, R.R. and M.E. Ondrusek. - 1996. Spatial and temporal variability of phytoplankton pigment distributions in the central equatorial Pacific ocean. Deep Sea Res. Part II, 43: 809-833.

Birch, D.A., W.R. Young and P.J.S. Franks. -2008 . Thin layers of plankton: Formation by shear and death by diffusion. Deep-Sec Res., I 55: 277-295.

Bracco, A., S. Clayton and C. Pasquero. - 2009. Horizontal advection, diffusion, and plankton spectra at the sea surface. J. Geophysical Res., 114: CO2001.

Cavender-Bares, K., D.M. Karl and S.W. Chisholm. - 2001. Nutrient gradients in the western North Atlantic Ocean: Relationship to microbial community structure and comparison to patterns in the Pacific Ocean. Deep-Sea Res. I, 48: 2373-2395.

Cermeño, P., E. Marañon, D. Harbour and R.P. Harris. - 2006 Invariant scaling of phytoplankton abundance and cell size in contrasting marine environments. Ecol. Lett., 9: 1210-1215.

Cheriton, O.M., M.A. McManus, M.T. Stacey, J.V. Steinbuck and J.P. Ryan. - 2009. Physical and biological controls on the maintenance and dissipation of a thin phytoplankton layer. Mar. Ecol. Progr. Ser., 378: 55-69.

Chisholm, S.W. - 1992. Phytoplankton size, In: P.G. Falkowski and A.D. Woodhead (eds.), Primary productivity and biogeochemical cycles in the sea. Plenum Press.

Cox, P.M., R.A. Betts, C.D. Jones and S.A.S.I.J. Totterdell. - 2000. Acceleration of global warming due to carbon-cycle feedbacks in a coupled climate model. Nature, 408: 184-187.

Davis, C.S. and D.J. McGillicuddy. - 2005. Transatlantic abundance of the $\mathrm{n}$-fixing colonial cyanobacterium Tricodesmium. Science, 312: 1517-1520.

DeLong, E.F., C.M. Preston, T. Mincer, V. Rich, S.J. Hallam, N. Freigaard, A. Martinez, M.B. Sullivan, R. Edwards, B.R. Brito, S.W. Chisholm and D.M. Karl. - 2006. Community genomics among stratified microbial assemblages in the ocean's interior. Science, 311: 496-503.

Demartini, E.E., A.M. Friedlander, S.A. Sandin and E. Sala. -2008. Differences in fish-assemblage structure between fished and unfished atolls in the northern line islands, central Pacific. Mar. Ecol. Progr. Ser., 365: 199-215.

Denman, K.L. and M.R. Abbot. - 1994. Time scales of pattern evolution from cross-spectrum analysis of advanced very high resolution radiometer and coastal zone color scanner imagery. J. Geophysical Res., 99: 7433-7442.

Denman, K.L., H.J. Freeland and D.L. Mackas. - 1989. Comparisons of time scales for biomass transfer up the marine food web and coastal transport processes. Can. Spec. Publ. Fish. Aquat. Sci., 108: 255-264.

Denman, K.L., A. Okubo and T. Platt. - 1977. The chlorophyll fluctuation spectrum in the sea. Limnol. Oceanogr., 22: 1033-1038.

Deutsch, C., J.L. Sarmiento, D.M. Sigman, N. Gruber and J.P. Donne. - 2007. Spatial coupling of nitrogen inputs and losses in the ocean. Nature, 445: 163-167.

Durham, W.M., J.O. Kessler and R. Stocker. - 2009. Disruption of vertical motility by shear triggers formation of thin phytoplankton layers. Science, 323: 1067-1070.

Edwards, A.M., T. Platt and D.G. Wright. - 2001. Biologically induced circulation at fronts. J. Geophysical Res., 106: 7081-7095.

Falkowski, P.G., R.T. Barber and V. Smetacek. - 1998. Biogeochemical controls and feedbacks on ocean primary production. Science, 281: 200-206.

Falkowski, P.G. and C. de Vargas. - 2004. Shotgun sequencing in the sea: A blast from the past? Science, 304: 58-60

Falkowski, P.G. and M.J. Oliver. - 2007. Mix and match: how climate selects phytoplankton. Nature Rev. Microbiol., 5: 813-818.

Fasham, M.J.R. - 2003. Ocean Biogeochemistry: the Role of the Ocean Carbon Cycle in Global Change. Springer Verlag, Berlin.

Finkel, Z. - 2007. Does phytoplankton cell size matter: The evolution of modern marine food webs. In: P.G. Falkowski and A.H. Knoll (eds.), Evolution of primary producers in the sea. Academic Press, San Diego, CA.

Flierl, G., D. Grünbaum, S.A. Levin and D. Olson. - 1999. From individuals to aggregations: the interplay between behavior and physics. J. Theoret. Biol., 196: 397-454.

Follows, M.J., S. Dutkiewicz, S. Grant and S.W. Chisholm. - 2007. Emergent biogeography of microbial communities in a model ocean. Science, 315: 1843-1846.

Franks, P.J.S. - 1995. Thin-layers of phytoplankton: a model of formation by near-inertial wave shear. Deep-Sea Res. I, 42: 75-91.

Franks, P.J.S. - 2002. Npz models of plankton dynamics: their construction, coupling to physics and application. J. Oceanogr., 58: 379-387.

Franks, P.J.S. - 2005. Plankton patchiness, turbulent transport and spatial spectra. Mar. Ecol. Progr. Ser., 294: 295-309.

Frias-Lopez, J., Y. Shi, G.W. Tyson, M.L. Coleman, S.C. Schuster, S.W. Chisholm and E.F. DeLong. - 2008. Microbial community gene expression in ocean surface waters. Proc. Nat. Acad. Sci. USA, 105: 3805-3810.

Fuhrman, J. - 1999. Marine viruses and their biogeochemical and ecological effects. Nature, 399: 541-548.

Fuhrman, J., I. Hewson, M.S. Schwalbach, J.A. Steele, M.V. Brown and S. Naeem. - 2006. Annually reoccurring bacterial communities are predictable from ocean conditions. Proc. Nat. Acad. Sci. USA, 103: 13104-13109.

Fuhrman, J.A., J.A. Steele, I. Hewson, M.S. Schwalbach, M.V. 
Brown, J.L. Green and J.H. Brown. - 2008. A latitudinal diversity gradient in planktonic marine bacteria. Proc. Nat. Acad. Sci. USA, 105: 7774-7778.

Geider, R.J. and J. LaRoche. - 2002. Redfield revisited: variability of $\mathrm{C}: \mathrm{N}: \mathrm{P}$ in marine microalgae and its biochemical basis. Eur. J. Phycol., 37: 1-17.

Gilbert, O.M. and E.J. Busky. - 2005. Turbulence decreases the hydrodynamic predator sensing ability of the calanoid copepod Acartia tonsa. J. Plankton Res., 27: 1067-1071.

Granata, T.C. and T.D. Dickey. - 1991. The fluid mechanics of copepod feeding in turbulent flow: A theoretical approach. Progr. Oceanogr., 26: 243-261.

Gruber, N. and J.L. Sarmiento. - 1997. Global patterns of marine nitrogen fixation and denitrification. Global Biogeochem. Cycles, 11: 235-266.

Grünbaum, D. - 1994. Translating stochastic density-dependent individual behavior to a continuum model of animal swarming. J. Math. Biol., 33: 139-161.

Grünbaum, D. - 2002. Predicting availability to consumers of spatially and temporally variable resources. Hydrobiologia, 480: 175-191.

Grünbaum, D. and A. Okubo. - 1994. Frontiers of Theoretical Biology, Lecture Notes in Biomathematics, volume 100, chapter Modelling social animal aggregations, Springer-Verlag.

Guadayol, O., F. Peters, J.E. Stiansen, C. Marrasé and A. Lohrmann. - 2009. Evaluation of oscillating grids and orbital shakers as means to generate isotropic and homogeneous small-scale turbulence in laboratory enclosures commonly used in plankton studies. Limnol. Oceanogr. Meth., 7: 287-303.

Haury, L.R., J.A. McGowan and P.H. Wiebe. - 1978. Patterns and processes in the time-space scales of plankton distributions. In: J.H. Steele (ed.), Spatial pattern in plankton communities. Plenum Press, pp. 277-327.

Hoegh-Guldberg, O. and J.F. Bruno. - 2010. The impact of climate change on the World's Marine Ecosystems. Science, 328: 1523-1528.

Huisman, J., M. Arrayas, U. Ebert and B. Sommeijer. - 2002. How do sinking phytoplankton species manage to persist? Am. Nat., 159: 245-254.

Hwang, J.S., J.H. Costello and J.R. Strickler. - 1994. Copepod grazing in turbulent flow: elevated foraging behavior and habituation of escape responses. J. Plankton Res., 16: 421-431.

Irwin, A.J., Z.V. Finkel, O.M.E. Schofield and P.G. Falkowski. 2006. Scaling-up from nutrient physiology to the size-structure of phytoplankton communities. J. Plankton Res., 28: 459-471.

Iversen, K.R., R. Primicerio, A. Larsen, J.K. Egge, F. Peters, O. Guadayol, A. Jacobsen, H. Havskum and C. Marrasé. - 2010. Effects of small-scale turbulence on lower trophic levels under different nutrient conditions. J. Plankton Res., 32: 197-208.

Jennings, S. and S. Mackinson. - 2003. Abundance-body mass relationships in size-structured food webs. Ecol. Lett., 6: 971-974.

Jiang, L., O.M.E. Schofield and P.G. Falkowski. - 2005. Adaptive evolution of phytoplankton cell size. Am. Nat., 166: 496-505.

Johnson, Z.I., E.R. Zinser, A. Coe, N.P. McNulty, E. Malcolm, S. Woodard and S.W. Chisholm. - 2006. Niche partitioning among Prochlorococcus ecotypes along ocean-scale environmental gradients. Science, 311: 173-1740.

Kamykowski, D., E.J. Milligan and R.E. Reed. - 1998. Relationships between geotaxis/photoaxis and diel vertical migration in autrophic dinflagellates. J. Plankton Res., 20: 1781-1796.

Kamykowski, D., R.E. Reed and G.J. Kirkpatrick. - 1992. Comparison of sinking velocity, swimming velocity, rotation and path characteristics among six marine dinoflagellate species. Mar. Biol., 113: 319-328

Karl, D.M., K.M. Bjorkman, J.E. Dore, L. Fujieki, D.V. Hebel, T. Houlihan, R.M. Letelier R.M. and L.M. Tupas. - 2001. Ecological nitrogen-to-phosphorus stoichiometry at station ALOHA. Deep-Sea Res. II, 48: 1529-1566.

Kerr, R.A. - 2010. Ocean acidification unprecedented, unsettling. Science, 328: 1500-1501.

Kerr, S.R. - 1974. Theory of size distribution in ecological communities. J. Fish. Res. Board Can., 31: 1859-1862.

Klausmeier, C.A., E. Litchman, T. Daufresne and S.A. Levin. - 2004. Optimal nitrogen-to-phosphorous stoichiometry of phytoplankton. Nature, 429: 171-174.

Kolmogorov, A.M. - 1941a. Dissipation of energy under locally isotropic turbulence. Dokl. Akad Nauk SSSR, 32: 16-18.
Kolmogorov, A.M. - 1941b. The local structure of turbulence in an incompressible fluid with very large Reynolds numbers. Dokl. Akad Nauk SSSR, 30: 301-305.

Lekan, J.F. and R.E. Wilson. - 1978. Spatial variability of phytoplankton biomass in the surface waters of long island. Estuar. Coast. Mar. Sci., 6: 239-251.

Leonard, C.L., C.R. McClain, R. Murtugudde, E.E. Hofmann and L.W. Harding. - 1999. An iron-based ecosystem model of the central equatorial Pacific. J. Geophys. Res., 104: 1325-1341.

Letelier, R.M., R.R. Bidigare, D.V. Hebel, M.E. Ondrusek, C.D. Winn and D.M. Karl. - 1993. Temporal variability of phytoplankton community structure based on pigment analysis. Limnol. Oceanogr., 38: 1420-1437.

Levin, S.A. - 1992. The problem of pattern and scale in ecology. Ecology, 73: 1943-1967.

Levin, S.A. - 1998. Ecosystems and the biosphere as complex adaptive systems. Ecosystems, 1: 431-436.

Levin, S.A. - 1999. Fragile Dominion: Complexity and the Commons. Perseus Books, Reading, MA.

Levin, S.A. - 2010. Crossing scales, crossing disciplines: collective motion and collective action in the global commons. Phil. Trans. Roy. Soc. Lond. B, 365: 13-18.

Levin, S.A. and J. Lubchenco. - 2008. Resilience, robustness, and marine ecosystem-based management. Bioscience, 58: 27-32.

Levin, S.A., A. Morin and T.H. Powell. - 1989. Patterns and process in the distribution and abundance of Antarctic krill, in Scientific Committee for the Conservation of Antarctic Marine Living Resources. In: Selected Scientific Papers, Part 1, 2nd edition, SC-CAMLR-SSP/5, CCAMLR, Hobart, Tasmania, Australia, pp. 281-299.

Li, W.K.W. - 2002. Macroecological patterns of phytoplankton in the northwestern North Atlantic Ocean. Nature, 419: 154-157.

Lima, I.D. and S.C. Doney. - 2004. A three-dimensional, multinutrient, and size-structured ecosystem model for the North Atlantic. Global Biogeochem. Cycles, 18: GB3019, doi:10.1029/2003GB002146.

Litchman, E., C.A. Klausmeier, J.R. Miller, O.M. Schofield and P.G. Falkowski. - 2006. Multi-nutrient, multi-group model of present and future oceanic phytoplankton communities. Biogeosciences, 3: 585-606.

Mackas, D.L. - 1984. Spatial autocorrelation of plankton community composition in a continental shelf ecosystem. Limnol. Oceanogr., 29: 451-471.

Mackas, D.L., R.E. Thomson and M. Galbraith. - 2001. Changes in the zooplankton community of the British Columbia continental margin, 1985-1999, and their covariation with oceanographic conditions. Can. J. Fish. Aquat. Sci., 58: 685-702.

Margalef, R. - 1978. Life-forms of phytoplankton as survival alternatives in an unstable environment. Oceanol. Acta, 1: 493-509.

Margalef, R., M. Estrada and D. Blasco - 1979. Functional morphology of organisms involved in red tides, as adapted to decaying turbulence. In: D.L. Taylor and H.H. Selinger (eds.) Toxic Dinoflagellate blooms, pp. 89-94. Elsevier/North Holland.

Martin, A.P. - 2003. Phytoplankton patchiness: the role of lateral stirring and mixing. Progr. Oceanogr., 57: 125-174.

McManus, M.A., R.M. Kudela, M.W. Silver, G.F. Steward, P.L. Donaghay and J.M. Sullivan. - 2008. Cryptic blooms: are thin layers the missing connection? Estuar. Coast., 31: 396-401.

Moison, M., F.G. Schmitt, S. Souissi, L. Seuront and J. Hwang. - 2009. Symbolic dynamics and entropies of copepod behavior under nonturbulent and turbulent conditions. J. Mar. Syst., 77: 388-396.

Moline, M.A., S.M. Blackwell, J.F. Chase, S.H.D. Haddock, C.M. Herren, C.M. Orrico and E. Terrill. - 2009. Bioluminescence to reveal structure and interaction of coastal planktonic communities. Deep Sea Res. Part II, 56: 232-245.

Moore, J.K., S.C. Doney, J.A. Kleypas, D.M. Glover and I.Y. Fung. - 2002. An intermediate complexity marine ecosystem model for the global domain. Deep-Sea Res. II, 49: 403-462.

Morel, F.M.M. - 1983. Principles of aquatic chemistry, John Wiley and Sons. Oschlies A. 2002. Can eddies make oceans bloom? Global Biogeochem. Cycles, 16: 1106.

Phillips, O.M. - 1991. The Kolmogorov spectrum and its oceanic cousins: a review. Proc. $R$. Soc. Lond. A, 434: 125-138.

Platt, T. and K. Denman. - 1977. Organisation in the pelagic ecosystem. Heloglander wiss. Meeresunters, 30: 575-581.

Pomeroy, L. - 1974. The ocean's food web, a changing paradigm. Bioscience, 24: 499-504. 
Pond, S. and G.L. Pickard. - 1983. Introductory dynamical oceanography, Butterworth Heinemann.

Poulin, F.J. and P.J.S. Franks. - 2010. Size-structured planktonic ecosystems: constraints, controls and assembly instructions. $J$. Plankton Res., 328.

Powell, T.M. and A. Okubo. - 1994. Turbulence, diffusion and patchiness in the sea. Phil. Trans. Roy. Soc. Lond. B, 343: 11-18.

Quigg, A., Z.V. Finkel, A.J. Irwin, Y. Rosenthal, T. Ho, J.R. Reinfelder, O. Schofield, F.M.M. Morel and P.G. Falkowski. 2003 The evolutionary inheritance of elemental stoichiometry in marine plankton. Nature, 425: 291-294.

Raven, J.A. and P.G. Falkowski. - 1999. Oceanic sinks for atmospheric CO2. Plant Cell Environ., 22: 741-755.

Redfield, A.C. - 1958. The biological control of chemical factors in the environment. Am. Sci., 46: 205-221.

Rinaldo, A., A. Maritan, K. Cavender-Bares, S.W. Chisholm. 2002. Cross-scale ecological dynamics and microbial size spectra in marine ecosystems. Proc. R. Soc. Lond. B, 269: 2051-2059.

Rodríguez, J. - 1994. Some comments on the size-based structural analysis of the pelagic ecosystem. Sci. Mar., 58: 1-10.

Rodríguez, J., J. Tintoré, J.T. Allen, J.M. Blanco, D. Gomis, A. Reul, J. Ruiz, V. Rodríguez, F. Echevarría and F. JiménezGómez. - 2001. Mesoscale vertical motion and the size structure of phytoplankton in the ocean. Nature, 410: 360-363.

Ryther, J.H. - 1969. Photosynthesis and fish production in the sea. Science 166: 72-76.

Sarmiento, J.L. and J.R. Toggweiler. - 1984. A new model for the role of the oceans in determining atmospheric pco2. Nature, 308: 621-624.

Scheffer, M., S. Rinaldi, J. Huisman and F.J. Weissing. - 2003. Why phytoplankton communities have no equilibrium: solutions to the paradox. Hydrobiologia, 491: 9-18.

Schmittner, A., A. Oschlies, X. Giraud, M. Eby and H.L. Simmons. - 2005. A global model of the marine ecosystem for long-term simulations: Sensitivity to ocean mixing, buoyancy forcing, particle sinking, and dissolved organic matter cycling. Global Biogeochem. Cycles, 19: GB3004.

Schofield, O.M.E., H.W. Ducklow, D.G. Martinson, M.P. Meredith, M.A. Moline and W.R. Fraser. - 2010. How do Polar Marine Ecosystems Respond to Rapid Climate Change? Science, 328: $1520-1523$

Seymour, J.R., Marcos and R. Stocker. - 2009. Resource patch formation and exploitation throughout the marine microbial food web. Am. Nat., 173: E15-E29.

Sheldon, R.W., A. Prakash and W. H. Sutcliffe J. - 1972. The size distribution of particles in the ocean. Limnol. Oceanogr., 17: 327-340.

Silvert, W. and T. Platt. - 1978. Energy flux in the pelagic ecosystem: A time-dependent equation. Limnol. Oceanogr., 23 813-816.

Smayda, T.J. - 1970. The suspension and sinking of phytoplankton in the sea. Oceanogr. Mar. Biol. Ann. Rev., 8: 353-414.
Smetacek, V. and U. Passow. - 1990. Spring bloom initiation and Sverdrup's critical-depth model. Limnol. Oceanogr., 35: 228-234.

Starr, J.L. and M.M. Mullin. - 1981. Zooplankton assemblages in three areas of the North Pacific as revealed by continuous horizontal transects. Deep-Sea Res., 28: 1303-1322.

Steele, J.H. and B.W. Frost. - 1977. The structure of plankton communities. Phil. Trans. Roy. Soc. Lond. B, 280: 485-534.

Stock, C.A., T.M. Powell and S.A. Levin. - 2008. Bottom-up and top-down forcing in a simple size-structured plankton dynamics model. J. Mar. Syst., 74: 134-152.

Stommel, H. - 1963. Varieties of oceanographic experience. Science, 139: 572-576.

Strom, S.L. - 2008. Microbial ecology of ocean biogeochemistry: A community perspective. Science, 320: 1043-1045.

Sullivan, J.M., P.L. Donaghay and J.E.B. Rines. - 2009. Coastal thin layer dynamics: Consequences to biology and optics. Cont. Shelf Res., 30: 50-65.

Sverdrup, H.U. - 1953. On conditions for the vernal blooming of phytoplankton. ICES J. Mar. Sci., 18: 287-295.

Taylor, L.R. - 1961. Aggregation, variance and the mean. Nature, 189: 732-735.

Tenneke, H. and J.L. Lumley. - 1972. A first course in turbulence. MIT Press.

Therriault, J., D.J. Lawrence and T. Platt. - 1978. Spatial variability of phytoplankton turnover in relation to physical processes in a coastal environment. Limnol. Oceanogr., 23: 900-911.

Thomas, W.H. and C.H. Gibson. - 1990. Quantified small-scale turbulence inhibits a red tide dinoflagellate, Gonyaulax polyedra Stein. Deep-Sea Res., 37: 1583-1593.

Vaillancourt, R.D., J. Marra, M.P. Seki, M.L. Parsons and R.B. Bidigare. - 2003. Impact of a cyclonic eddy on phytoplankton community structure and photosynthetic competency in the subtropical North Pacific Ocean. Deep-Sea Res. I, 50: 829-847.

Walsh, J.J. - 1981. A carbon budget for overfishing off Peru. Nature, 290: 300-304.

Weber, L.H., S.Z. El-Sayed and I. Hampton. - 1986. The variance spectra of phytoplankton, krill and water temperature in the Antarctic Ocean south of Africa. Deep-Sea Res., 33: 1327-1343.

Wroblewski, J.S., J.J. O'Brien and T. Platt. - 1975. On the physical and biological scales of phytoplankton patchiness in the ocean. Mem. Soc. Roy. Sci. Liege, 6: 43-57.

Yoder, J.A., C.R. McClain, J.O. Blanton and L. Oey. - 1987. Spatial scales in CZCS-chlorophyll imagery of the southeastern U.S. continental shelf. Limnol. Oceanogr., 32: 929-941.

Yoshiyama, K. and C.A. Klausmeier. - 2008. Optimal cell size for resource uptake in fluids: a new facet of resource competition. Am. Nat., 171: 59-70.

Scient. ed.: F. Peters

Received January 10, 2011. Accepted July 7, 2011.

Published online September 13, 2011 